\title{
IDENTIFICAÇÃO DE ÁREAS ADEQUADAS \\ À IMPLANTAÇÃO DE INFRA-ESTRUTURA \\ ARQUITETÔNICA ATRAVÉS DO USO DO SISTEMA \\ DE INFORMAÇÃO GEOGRÁFICA (SIG): \\ ESTUDO DE CASO - PARQUE NACIONAL \\ SAINT-HILAIRE/LANGE - PARANÁ \\ Choise of adequate areas to the implementation \\ of the architectural structure through \\ the Geographic Information Sistem (GIS): \\ the case of Saint-Hilaire/Lange National Park - Paraná
}

\author{
Ivana Maria de Paula Souza GUIMARÃES 1
}

Sony Cortese CANEPARO²

\begin{abstract}
RESUMO
Com o objetivo de desenvolver uma proposta metodológica para subsidiar a escolha de áreas adequadas à implantação da infraestrutura arquitetônica (centro de visitantes, estacionamento, alojamentos, sede administrativa, oficinas, entre outros) dentro de uma Unidade de Conservação de Proteção Integral - Parque Nacional Saint-Hilaire/Lange, localizado no litoral do estado do Paraná - Brasil, foram utilizadas técnicas participativas de apoio à decisão em SIG (Sistema de Informação Geográfica), através da análise conjunta de variáveis (vegetação, declividade, solo, distância de rios e estradas) aplicando-se a técnica de avaliação por múltiplos critérios denominada COMBINAÇÃO LINEAR PONDERADA. Os resultados evidenciam a identificação de áreas com diferentes graus de adequabilidade.
\end{abstract}

\section{Palavras-chave:}

SIG; geoprocessamento; combinação linear ponderada; zoneamento ambiental; unidade de conservação.

\begin{abstract}
The goal was to develop a methodological proposal to subsidize the choice of adequate areas in the implementation of architectural structures (visitor's center, parking lot, housing, administrative shops, among others) inside a Preservation Unit of Full Protection - Sáint Hilaire/Lange, located on the coast of the State of Parana - Brazil. Participative techniques of support were used for the decision in GIS (Geographic Information System), with the combined analysis of variables, (vegetation, declivity, ground, river distances and roads) by applying the technique of evaluation with multiple criteria, known as Weight Linear Combination. The results show the findings of areas with different aptitude degrees.
\end{abstract}

\section{Key words:}

GIS; geoprocessing; weight linear combination; environmental zoning; preservation unit.

1 Arquiteta e Urbanista pela UFPR, Mestre em Geografia, Setor de Ciências da Terra da Universidade Federal do Paraná. 2 Geógrafa pela UFPR, Profa. Dra. do Departamento de Geografia da Universidade Federal do Paraná. 
GUIMARÃES, I. M, P.; CANEPARO, S. C. Identificação de áreas adequadas à implantação de infra-estrutura...

\section{INTRODUÇÃO}

"Um empreendimento deve ser analisado quanto aos riscos de sua instalação para a natureza e os riscos que a natureza oferece à presença do empreendimento naquele lugar" (ROSS, 2000).

Neste cenário, onde a ação antrópica sobre o meio físico, remodela e organiza paisagens naturais, muitas vezes, desencadeiam-se inúmeros processos indesejáveis pela inexistência de um planejamento ambiental adequado, implicando em problemas às vezes irreversíveis para o meio natural.

De acordo com Ross (1990) o planejamento não pode ser formulado a partir de uma leitura estática do ambiente, mas inserido no entendimento do processo de ocupação que norteia o desenvolvimento e a apropriação do território e de seus recursos.

O planejamento ambiental emprega como instrumento todas as informações disponíveis sobre a área de estudo, vindas das mais diversas áreas do conhecimento. E deve levar em conta não apenas as potencialidades da área - mas principalmente suas restrições (FRANCO, 2001).

A tecnologia do Sistema de Informação Geográfica (SIG) propicia a geração de dados que servem de apoio à tomada de decisões nos mais diferentes projetos que tratam da questão ambiental. A obtenção rápida de mapas georreferenciados e a possibilidade de uma avaliação integrada de um grande número de variáveis, torna vantajoso o uso deste sistema, que ainda oferece a oportunidade de revisar, incluir e atualizar dados em qualquer etapa do trabalho, transformando-se em uma valiosa ferramenta através da disponibilização dos dados gerados que podem vir a auxiliar pesquisas posteriores.

No intuito de conservar e ou preservar determinadas áreas cuja biodiversidade é considerada de significativa importância foi estabelecido, em 18 de julho de 2000, o Sistema Nacional de Unidades de Conservação (SNUC) regulamentado pela Lei n. 9.985, estabelecendo critérios e normas para a criação - a implantação e gestão das Unidades de Conservação (UC).

Os Parques Nacionais (PARNAS) que se enquadram como uma Unidade de Conservação de Proteção Integral, tem como objetivos do seu manejo: proteger e preservar valores naturais e recursos genéticos, facilitar a investigação científica, desenvolver a educação ambiental e oferecer oportunidades para a recreação pública.
A implantação da infra-estrutura básica de administração e de apoio à visitação dentro de uma UC é sempre impactante, mas para que o impacto desta ação antrópica sobre o meio possa ser minimizado, o planejador precisa ter acesso a diversas alternativas, para fazer escolhas responsáveis em benefício da natureza e do homem.

Nesta linha é que se propõe o estudo sobre o Parque Nacional Saint-Hilaire/Lange, Unidade de Conservação de Proteção Integral, que de acordo com Mittemeier ${ }^{3}$ et al. (1999) citado por Siedlecki, Portes e Cielo Filho (2003a) está inserido na áreanúcleo da Reserva da Biosfera da Mata Atlântica, em um dos trechos mais bem conservados deste bioma no país. Localiza-se na porção Leste do estado do Paraná na região de Floresta Costeira, mais ao sul da Serra do Mar, dentro da Área de Proteção Ambiental (APA) de Guaratuba, compreendendo parte dos municípios de Matinhos, Guaratuba, Morretes e Paranaguá.

Foi criado pela Lei Federal n. 10.277 de 23/05/2001, com a finalidade de "proteger e conservar ecossistemas da Mata Atlântica e assegurar a estabilidade ambiental dos balneários sob sua influência, bem como a qualidade de vida das populações litorâneas".

Neste sentido, a pesquisa tem por objetivo geral, desenvolver uma proposta metodológica através da avaliação do meio físico, na qual possam ser elencadas potencialidades e restrições que subsidiem a definição de áreas adequadas à implantação da infra-estrutura arquitetônica através do Sistema de Informação Geográfica (SIG).

\section{LOCALIZAÇÃO E CARACTERIZAÇÃO GERAL DA ÁREA}

O Parque Nacional Saint-Hilaire/Lange foi concebido sobre o domínio da Serra da Prata, parte da sub-região montanhosa litorânea da Serra do Mar, entre as coordenadas UTM $7.172 .450 \mathrm{mN}, 7.138 .060 \mathrm{mN}$ e $746.340 \mathrm{mE}, 726.350 \mathrm{mE}$. E entre as coordenadas geográficas $25^{\circ} 30^{\prime} 00^{\prime \prime} \mathrm{S}, 48^{\circ} 45^{\prime} 00^{\prime \prime} \mathrm{W}$, e $25^{\circ} 52^{\prime} 30^{\prime \prime} \mathrm{S}$, $48^{\circ} 30^{\prime} 00^{\prime \prime}$. Distando apenas $80 \mathrm{Km}$ da capital do estado do Paraná (Curitiba) e cerca de $20 \mathrm{Km}$ da cidade portuária de Paranaguá (IBAMA, 2006).

3 MITTEMEIER, R. A.; FONSECA, G. A. B. da; RYLANDS, A. B. \& MITTEMEIER, C. G. Atlantic Forest. In: R. A. Mittemeier, N. Myers, P. Robles Gil \& C.G. Mittemeier (Eds.), Hotspots: earth's biologically richest and most endangered terrestrial ecoregions. CEMEX, Mexico City, 1999. p. $136-145$. 
O PARNA foi inicialmente criado abrangendo uma área de 25.000 ha. Em meados do ano de 2003 a equipe responsável pela gestão da unidade encaminhou ao Poder Executivo uma proposta de adequação dos seus limites legais, ampliando sua área para 35.888 ha. Segundo Bornschein, Reinert e Olmos (2003), "a nova configuração torna o parque uma das poucas Unidades de Conservação (UCs) de proteção integral no Bioma Floresta Atlântica a incluir todo o gradiente de habitats desde o nível do mar até o topo das serras ...".

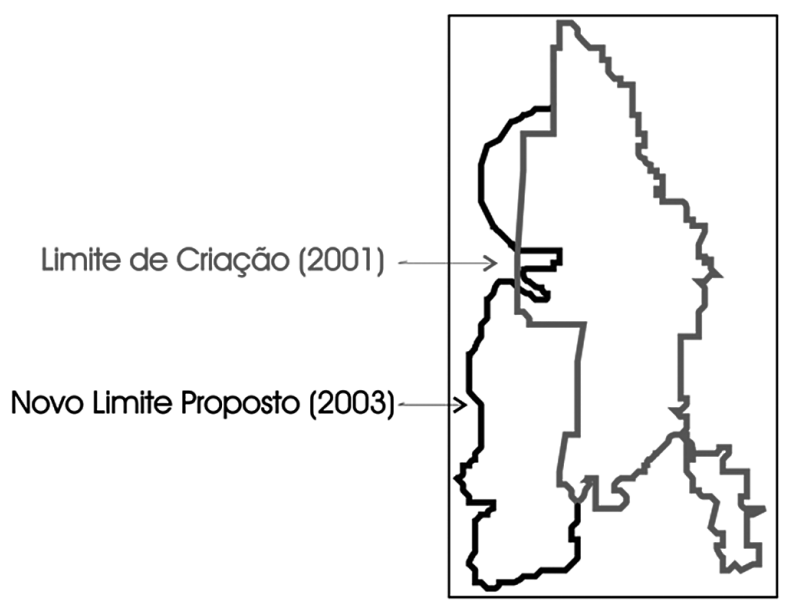

FIGURA 1 - PROPOSTA DE NOVOS LIMITES PARQUE NACIONAL SAINT-HILAIRE/LANGE

A malha viária confere um caráter quase insular a área, como se pode observar na Figura 2. A rodovia federal BR277 tangencia sua face norte e a rodovia estadual PR-508 segue paralela em sua face leste. A borda ocidental é ladeada pela estrada da Limeira, desprovida de revestimento asfáltico. E ao sul, tem como limite natural a Baía da Guaratuba.

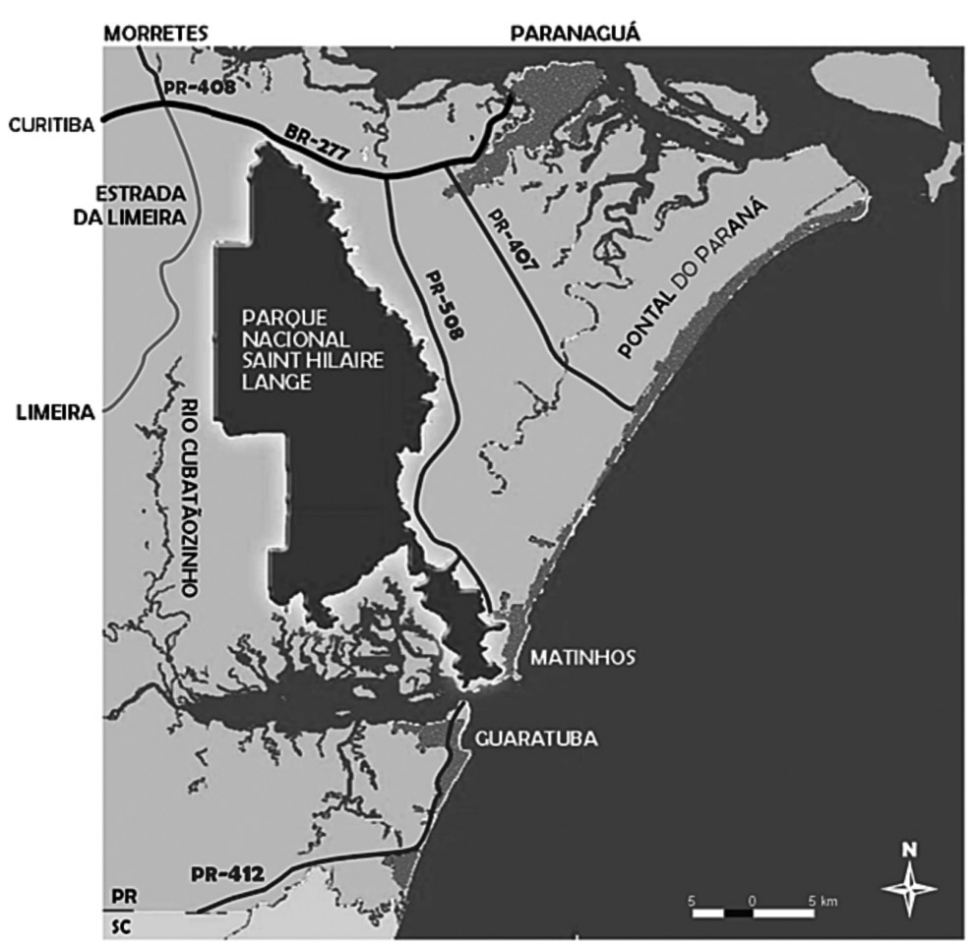

FIGURA 2 - LOCALIZAÇÃO DO PARQUE NACIONAL SAINT-HILAIRE/LANGE

FONTE: SIEDLECKI, PORTES E CIELO FILHO (2003a). 
GUIMARÃES, I. M, P.; CANEPARO, S. C. Identificação de áreas adequadas à implantação de infra-estrutura...

O relevo da Serra da Prata é caracterizado por grandes desníveis e altas declividades, geralmente superiores a $45 \%$. A maior altitude está representada pelo Morro Grande que atinge 1502 m.s.n.m.

Quanto a rede de drenagem, Bigarella et al (1978) esclarece que o sistema hidrográfico da Bacia Atlântica está inserido entre a Serra do Mar e a planície litorânea, drenando o leste do estado do Paraná. Este sistema é considerado geologicamente recente em relação às demais bacias do estado. ABacia Atlântica pode ser subdividida em seis sub-bacias, a saber: Ribeira, Baía das Laranjeiras, Baía de Antonina, Nhundiaquara, Baía de Paranaguá e Baía de Guaratuba. Sendo apenas a da Ribeira a que não tem suas águas direcionadas as Baías de Guaratuba ou de Paranaguá (BIGARELLA et.al, 1978). O mesmo autor observa que na drenagem leste paranaense a maior parte dos rios encontra suas nascentes inseridas nas encostas da serra perto dos topos, cujo escoamento é predominantemente retilíneo e se faz em áreas de grande declividade.

Relatos históricos contam que a área em estudo guarda expressiva importância metalogenética, havendo registros de ocorrências de ouro, prata e chumbo (LOPES; LIMA, 1985). As vertentes da Serra da Prata são revestidas por solos em geral de baixa fertilidade e alto percentual de alumínio, historicamente utilizados para culturas de subsistência. São encontrados: Cambissolos, Podzólicos, Latossolos, Hidromórficos, Mangue e Afloramento de Rocha (EMBRAPA, 1984).

Quanto a vegetação predominante na região, destaca-se a formação da Floresta Ombrófila Densa, que apresenta remanescentes de grande interesse para a conservação da natureza no estado, concentrando-se nas planícies litorâneas e nas serras, definida em quase toda sua extensão pela barreira natural da Serra do Mar (SIEDLECKI; PORTES; CIELO FILHO, 2003b).

\section{MATERIAIS E PROCEDIMENTOS METODOLÓGICOS}

Diante da necessidade de conhecer e compreender a organização espacial da área em estudo, o Parque Nacional Saint-Hilaire/Lange, foi possível obter, através de um convênio entre o IBAMA e a MINEROPAR Serviço Geológico nos Municípios (2005), o acesso ao levantamento do meio físico realizado exclusivamente sobre esta Unidade de Conservação. Este levantamento baseou-se na proposta da equipe gestora para a adequação dos limites legais do parque em 2003.

Os dados obtidos, de interesse para esta pesquisa já em base digital, foram o limite (perímetro) da área, a rede de drenagem, a malha viária e as curvas de nível cotadas, baseadas nas Folhas Topográficas de
Paranaguá e Guaratuba, na escala 1:50.000, do DSG, anos de 1998 e 1969, respectivamente, MI 2858-2 e 2858-4.

O mapa de vegetação, foi gerado com base nos arquivos digitais da Série Cartas da Vegetação do Paraná (Sul), na escala 1:50.000, da Secretaria de Estado do Meio Ambiente e Recursos Hídricos - SEMA, Programa Proteção da Floresta Atlântica - PRÓ-ATLÂNTICA. Mapeamento baseado na interpretação de imagens de satélite LandSat datadas de 1999 e acurada checagem de campo.

Para a espacialização do mapa de solos, utilizou-se a base digital do Mapa Compilado de Solos da Área de Proteção Ambiental - APA de Guaratuba (SCHMIDLIN, 1998) na escala 1:50.000, fornecido pela SEMA - Departamento de Cartografia e Geoprocessamento. Já que o parque encontra-se totalmente inserido dentro da APA.

O software adotado para a realização da análise geográfica e processamento de imagens foi o Idrisi Andes - Sistema de Tratamento de Imagens e Sistema Geográfico de Informações, desenvolvido pela Clark University - Massachucets.

O software Arcview 3.2 - Sistema Geográfico de Informações, desenvolvido pelo ESRI - Environmental Systems Research Institute. Foi utilizado na confecção dos mapas temáticos.

A metodologia utilizada para atingir o objetivo proposto será a análise por múltiplos critérios denominada Combinação Linear Ponderada, a qual atende a decisão de localização quando objetivos múltiplos estão envolvidos.

De acordo com Weber e Hasenack (1999), os critérios representados são de dois tipos:

a) Restrições (limitações absolutas) são aqueles critérios Booleanos que limitam a análise a regiões específicas. Diferenciando áreas que podem ser consideradas adequadas das que não são adequadas sob condição alguma.

b) Fatores, entretanto, são critérios que definem algum grau de aptidão, para toda área considerada. Definindo áreas em termos de uma medida contínua de aptidão, que pode ser ressaltada ou diminuída, isto é, consideram-se áreas que estavam fora das restrições absolutas quando se adota, comparativamente, critérios Booleanos na análise.

Essa metodologia permite combinar e comparar todos os fatores que devem ser avaliados. Faz-se, portanto, necessária uma padronização dos critérios não comparáveis entre si viabilizando a agregação entre eles. A maior parte dos processos de padronização utiliza-se de um valor máximo e mínimo para a definição de uma escala. O pro- 
GUIMARÃES, I. M, P.; CANEPARO, S. C. Identificação de áreas adequadas à implantação de infra-estrutura...

cesso de padronização é na sua essência a lógica Fuzzy, segundo a qual um conjunto de valores pode ser expresso (convertido) em uma escala normalizada, tornando-os comparáveis Para este processo existem várias funções Fuzzy que podem ser utilizadas, sendo as mais conhecidas: sigmoidal, j-shaped, linear e complexa.

Na construção da regra de decisão define-se o modo como os diversos fatores serão combinados entre si, a fim de atingir o objetivo proposto. Por exemplo, o proposito é a localização da maior quantidade de áreas, destinadas a implantação da infra-estrutura, porém há a necessidade de que estas áreas estejam primeiramente fora das zonas de restrição e próximas às estradas, que estejam localizadas em áreas com maior grau de antropização da cobertura vegetal, onde a declividade não seja muito elevada e com solos mais resistentes a processos erosivos. Todas estas considerações devem ser incorporadas no processo de construção da regra de decisão, valorando-se cada fator de acordo com a sua importância diante do cenário pretendido (WEBER; HASENACK, 1999).

Efetua-se a ponderação através da comparação pareada entre os fatores, comparados relativamente uns aos outros, sempre dois a dois. Segundo Weber e Hasenack (1999), este tipo de comparação permite estabelecer qual é o fator mais significativo e quanto cada um é mais importante que os demais em termos relativos e como os fatores irão compensar-se uns aos outros. Fatores com aptidão elevada em uma determi- nada área, podem compensar outros fatores com baixa aptidão neste mesmo local. (EASTMAN, 1998)

O processo resulta em um peso para cada fator e uma avaliação de consistência da comparação pareada. A razão de consistência ( $C R$ - Consistency Ratio) tem por finalidade informar ao usuário sobre quaisquer inconsistências ocorridas durante a atribuição de pesos. Segundo Saaty \& Vargas ${ }^{4}$, (1991) citado por Zambon, (2005), quando o CR é superior a 0,1 é necessário reavaliar o processo. Esta afirmação foi feita baseando-se em vários contextos em que se utilizou este método para a resolução de diferentes tipos de problemas complexos.

\section{DESCRIÇÃO E ANÁLISE DAS VARIÁVEIS DO MEIO FÍSICO}

A fim de subsidiar a escolha de áreas adequadas à implantação da infra-estrutura arquitetônica dentro da área do Parque Nacional Saint-Hilaire/Lange, 5 variáveis foram consideradas (vegetação, declividade, solos, distância de rios e distância de estradas) e cada uma com a identificação de parâmetros balizadores que serão utilizados para facilitar a definição de áreas potencialmente viáveis.

a) Vegetação: foram encontradas 16 classes, as quais foram ordenadas em ordem crescente de aptidão à implantação da infra-estrutura, em função do tipo de cobertura vegetal identificada.

\begin{tabular}{ccc}
\hline VEGETAÇÃO & ÁREA (hectares) & ÁREA (\%) \\
\hline F.O.D Terras Baixas (SH) & 104.8 & 0.3 \\
F.O.D Terras Baixas (SSH, NH) & 845.5 & 2.4 \\
F.O.D Aluvial & 1494.4 & 4.2 \\
F.O.D Submontana & 22428.0 & 62.9 \\
F.O.D Montana & 3164.6 & 8.9 \\
F.O.D Altomontana & 99.2 & 0.3 \\
Campos de Altitude & 9.7 & 0.0 \\
F.P.I m Campos Salinos & 270.7 & 3.2 \\
F.P.I m Manguezais & 1157.1 & 1.7 \\
F.P.I.F Várzeas & 588.5 & 2.5 \\
F.P.I.F Caxetais & 893.9 & 0.1 \\
F.P.I.M Restinga (herb. Arb.) & 18.7 & 0.1 \\
F.P.I.M Restinga Arbórea & 22.6 & 3.7 \\
Fase Inicial de Capoeira & 1304.9 & 8.9 \\
Fase Intermediária de Capoeirão & 3164.8 & 0.2 \\
Agropecuária e Outros & 74.4 & \\
\hline
\end{tabular}

QUADRO 1 - COBERTURA VEGETAL DO PARQUE NACIONAL SAINT-HILAIRE/LANGE

FONTE: Série Cartas da Vegetação do Paraná - Sul (2003), SEMA. Adaptação da autora.

4 SAATY, T. L. \& VARGAS, L.G. Prediction, Projection and Forecasting. Kluwer Academic Boston, MA, USA, 1991. 
GUIMARÃES, I. M, P.; CANEPARO, S. C. Identificação de áreas adequadas à implantação de infra-estrutura...

As classes identificadas como Fase Inicial de Capoeira, Fase Intermediária de Capoeirão, Agropecuária e Outros, por se encontrarem bastante antropizadas, foram consideradas as mais adequadas a servir de suporte para a implantação da infra-estrutura arquitetônica. Perfazendo um total de 4.544,1 hectares, correspondentes a $12,8 \%$ do total. Todos os demais tipos de cobertura vegetal foram considerados potencialmente inferiores em relação ao objeto da pesquisa

b) Declividade: foram estabelecidas cinco classes de declividade as quais seguiram os critérios adotados por De Biasi (1992), como mostra a Tabela 2:

\begin{tabular}{|c|c|c|}
\hline CLASSES DE DECLIVE (\%) & $\begin{array}{c}\text { ÁREA } \\
\text { (hectares) }\end{array}$ & $\begin{array}{c}\text { ÁREA } \\
(\%)\end{array}$ \\
\hline $0 \%-5 \%$ & 6035.9 & 16.9 \\
\hline $5 \%-12 \%$ & 2550.6 & 7.2 \\
\hline $12 \%-30 \%$ & 9013.9 & 25.3 \\
\hline $30 \%-47 \%$ & 9811.9 & 27.5 \\
\hline Maior $47 \%$ & 8229.3 & 23.1 \\
\hline
\end{tabular}

QUADRO 2 - CLASSES DE DECLIVE - PARQUE NACIONAL SAINT-HILAIRE/LANGE

FONTE: DE BIASI, (1992) . Adaptação da Autora.

As características ideais do terreno pertencem a classe de declividade de 0 a $5 \%$, de relevo plano. Porém a instalação de infra-estruturas em declividades superiores, estabelecendo-se um limite de até $30 \%$ podem ser consideradas, levando-se em conta uma maior dificuldade construtiva, declividades superiores a $30 \%$ foram desconsideradas da análise, já que as técnicas empregadas podem ocasionar problemas de diversas ordens ao meio ambiente.

c) Solos: na área do PARNA foram classificadas as unidades de mapeamento de solo, ordenadas em ordem crescente em relação ao potencial erosivo, descritas na (TABELA 3).

\begin{tabular}{|c|c|c|c|}
\hline & UNIDADES DE MAPEAMENTO & $\begin{array}{c}\text { ÁREA } \\
\text { (hectares) }\end{array}$ & $\begin{array}{c}\text { ÁREA } \\
(\%)\end{array}$ \\
\hline 1 & PVa1 & 2874.4 & 8.1 \\
\hline 2 & Ca12 + LVa3 & 607.5 & 1.7 \\
\hline 4 & Cd11 + PVa3 & 126.1 & 0.4 \\
\hline 5 & Ca11 + PVa3 & 1063.3 & 3.0 \\
\hline 6 & Ca12 + PVa3 & 670.3 & 1.9 \\
\hline 7 & Ca26 + PVa3 & 201.5 & 0.6 \\
\hline 8 & Ca24 + PVa3 & 713.4 & 2.0 \\
\hline 9 & Ca31 & 591.4 & 1.7 \\
\hline 10 & Ca9 & 210.9 & 0.6 \\
\hline 11 & Ca11 & 4538.7 & 12.7 \\
\hline 12 & Ca12 & 4433.4 & 12.4 \\
\hline 13 & $\mathrm{Ca} 12+\mathrm{Ca} 22$ & 7506.8 & 21.1 \\
\hline 14 & Ca17 & 45.5 & 0.1 \\
\hline 15 & Ca21 & 154.7 & 0.4 \\
\hline 16 & Ca14 + Ca9 & 1648.4 & 4.6 \\
\hline 17 & Ca12 + Ra8 & 855.5 & 2.4 \\
\hline 18 & Ca17 + Ra8 & 199.4 & 0.6 \\
\hline 19 & Ca24 +Ra10 & 204.5 & 0.6 \\
\hline 20 & Ca30 +Re1 & 37.3 & 0.1 \\
\hline
\end{tabular}


GUIMARÃES, I. M, P.; CANEPARO, S. C. Identificação de áreas adequadas à implantação de infra-estrutura...

\begin{tabular}{cccc} 
(conclusão) & & & \\
\hline 21 & Ca12 + Ca28 + Ra8 & 1985.3 & 5.6 \\
22 & Ca12 + PVa3 + AR1 & 112.1 & 0.3 \\
23 & Ca22 + Ra8 + AR1 & 110.1 & 0.3 \\
24 & Ca8 + Ra11 + AR1 & 487.3 & 1.4 \\
25 & Ca9 + HGP2 & 189.1 & 0.6 \\
26 & Ra1 & 140.5 & 0.4 \\
27 & Ra4 + AR1 & 412.3 & 1.2 \\
28 & AR1 + Ra1 & 356.4 & 1.0 \\
29 & HGP2 + Ca14 & 3947.6 & 11.1 \\
30 & HGP1 + Ad1 & 1278.2 & 3.6 \\
31 & $\mathrm{P}+\mathrm{PH} 1$ & 128.6 & 0.4
\end{tabular}

QUADRO 3 - UNIDADES DE MAPEAMENTO DE SOLOS - PARQUE NACIONLA SAINT-HILAIRE/LANGE

FONTE: Mapa Compilado de Solos da Área de Proteção Ambiental - APA de Guaratuba (SCHMIDLIN,1998), SEMA. Adaptação da autora.

As classes que apresentam solos HIDROMÓRFICOS (HGP2+Ca14 / HGP1+Ad1 / P+PH1) aparecem com menor potencial na classificação, por estarem fora das características que são objeto desta pesquisa, uma vez que em grande parte do ano o lençol freático encontra-se próximo à superfície, fato que dificultaria e oneraria significativamente a implantação da infraestrutura, tendo em vista a execução de fundações, locação do canteiro de obra, acesso de pessoal e de material. A alternativa de rebaixamento do lençol freático certamente causaria maior impacto ao meio ambiente. Inclui-se nesta classificação as áreas de MANGUE, que segundo Palmieri e Larach (2000), além de distribuíremse em áreas sedimentares pantanosas e alagadas, estão sujeitas à influência permanente das marés, e por apresentarem características bióticas únicas e serem consideradas como um sustentáculo da atividade pesqueira, são protegidas por lei.

Observa-se uma predominância de CAMBISSOLOS ÁLICOS e DISTRÓFICOS, os quais também aparecem em diversas áreas com associações de LVa3 - LATOSSOLO VERMELHO-AMARELO ÁLICO ou PVA3 - PODZÓLICO VERMELHO-AMARELO ÁLICO conferindo a unidade um caráter menos limitante a processos erosivos, portanto mais apta ao objetivo proposto.

A classe 1 - PVa1 - PODZÓLICO VERMELHO AMARELO ÁLICO Tb A moderado textura argilosa e/ou muito argilosa, são solos minerais bem desenvolvidos e bem drenados, aparecem em vertentes com declividades menos acentuadas apresentando-se como o melhor solo da área do PARNA, com vistas a implantação da infra-estrutura arquitetônica.

Para efeito da aplicação desta metodologia as unidades de mapeamento PVa1, Ca12+LVa3, Cd11+PVa3, $\mathrm{Ca} 11+\mathrm{PV} 33, \mathrm{Ca} 12+\mathrm{PV} 33$, foram consideradas as mais adequadas, por apresentarem, entre as outras unidades encontradas um caráter menos expressivo quanto a ocorrência de processos erosivos. d) Distância de rios: De acordo com a Legislação Federal sobre o Meio Ambiente (Lei n. 4.771, de 15 de setembro de 1965, art. $2 .^{\circ}$ do Código Florestal, já alterada pela Lei n. 7.803 de 1989), ao redor de nascentes ainda que intermitentes, e nos chamados olhos d'água, qualquer que seja sua situação topográfica, existe uma área de preservação com $50 \mathrm{~m}$ de largura. Quanto à cursos d'água a mesma lei estabelece as larguras necessárias de preservação, sendo definidas proporcionalmente à largura dos cursos d'água existentes, conforme a especificação abaixo:

- $30 \mathrm{~m}$ para cursos d'água menores que $10 \mathrm{~m}$

- $50 \mathrm{~m}$ para cursos d'água de $10 \mathrm{~m}$ a $50 \mathrm{~m}$

- 100 m para cursos d'água de $50 \mathrm{~m}$ a $200 \mathrm{~m}$

- 200 m para cursos d'água de $200 \mathrm{~m}$ a $600 \mathrm{~m}$

- $500 \mathrm{~m}$ para cursos d'água maiores que $600 \mathrm{~m}$ de largura

Foram identificados importantes rios como o Cambará, Guaraguaçu, do Meio, das Pombas, entre outros, porém, não chegam a atingir largura superior a $50 \mathrm{~m}$. Diante deste fato, optou-se por considerar a área correspondente a 50 metros do rio (área de Preservação Permanente) como restrição, ou seja, não será considerada adequada à implantação da infra-estrutura sob condição alguma.

e) Distância de estradas: As estradas estão localizadas predominantemente na vertente oriental do perímetro do PARNA, sendo um das principais vias de acesso a rodovia PR 508: Alexandra - Matinhos, da qual partem um número expressivo de estradas secundárias que em sua maioria chegam aos limites da UC.

A fim de evitar um impacto ambiental mais acentuado, considerou-se que as áreas adequadas, devem estar próximas às estradas ou caminhos já existentes, os quais além da facilidade de acesso, contam com a existência de rede elétrica e de abastecimento de água, reduzindo os custos operacionais para viabilizar um can- 
GUIMARÃES, I. M, P.; CANEPARO, S. C. Identificação de áreas adequadas à implantação de infra-estrutura...

teiro de obra. As áreas consideradas adequadas estão limitadas a uma distância máxima de 200 metros, da estrada e uma faixa correspondente a $15 \mathrm{~m}$ de largura, por toda a extensão da estrada (leito de rodagem mais recuos), foi desconsiderada da análise, e aparece como uma restrição, ou seja, não serão consideradas áreas adequadas, sob condição alguma.

\section{AVALIAÇÃO POR MÚLTIPLOS CRITÉRIOS ATRAVÉS DA COMBINAÇÃO LINEAR PONDERADA}

Para viabilizar a integração de todas as variáveis deste trabalho, as mesmas foram padronizadas para uma mesma escala de valores, já que cada critério encontra- se em uma escala diferente (classes, porcentagem, metros). Esta padronização é efetuada pela rotina Fuzzy, com a qual é possível redimensionar a imagem colocando-a dentro de um intervalo de 0 a 255 níveis, considerando sempre valores mais próximos de 255 como sendo áreas mais aptas.

Após a padronização procedeu-se a determinação de pesos para cada variável, para tanto é necessário estabelecer qual delas é mais importante que as demais em termos relativos e como podem compensar-se umas as outras.

\begin{tabular}{|c|c|c|c|c|c|}
\hline & FUZZY VEGETAÇÃO & $\begin{array}{c}\text { FUZZY } \\
\text { DECLIVIDADE }\end{array}$ & $\begin{array}{c}\text { FUZZY } \\
\text { SOLOS }\end{array}$ & $\begin{array}{c}\text { FUZZY } \\
\text { DIST. RIOS }\end{array}$ & $\begin{array}{c}\text { FUZZY } \\
\text { DIST.ESTRADAS }\end{array}$ \\
\hline FUZZY VEGETAÇÃO & 1 & 1 & & \\
\hline FUZZY DECLIVIDADE & $1 / 2$ & $1 / 2$ & 2 & 1 & $1 / 2$ \\
\hline $\begin{array}{c}\text { FUZZY } \\
\text { SOLOS }\end{array}$ & $1 / 3$ & 2 & 2 & 1 \\
\hline $\begin{array}{c}\text { FUZZY } \\
\text { DIST. RIOS }\end{array}$ & 1 & 1 & & 1 \\
\hline $\begin{array}{c}\text { FUZZY } \\
\text { DIST.ESTRADAS }\end{array}$ & 1 & & & \\
\hline
\end{tabular}

QUADRO 4 - DETERMINAÇÃO DOS PESOS DE IMPORTÂNCIA RELATIVA

Na técnica de comparação pareada são estabelecidos os pesos das variáveis, como mostra o Quadro 1, permitindo um processo interativo de exploração, ou seja, pode-se refazer o cálculo dos pesos, retornando a matriz de comparação pareada, quanta vezes julgar necessário.

Tem-se como exemplo no Quadro 1, que a variável Distância de Rios é considerada duas vezes mais importante que a Variável Solos. Isto pelo fato de que quanto mais distante de um rio, uma área adequada a implantação da infra-estrutura se encontrar, menores serão os impactos ambientais sobre área de preservação permanente, sob esta ótica a variável solo perde significativamente sua importância. Os pesos calculados são determinados pelo programa (Quadro 2) e resultam em uma avaliação de consistência da comparação pareada.

\begin{tabular}{|c|c|}
\hline & PESOS CALCULADOS \\
\hline FUZZY VEGETAÇÃO & 0.2670 \\
\hline FUZZY DECLIVIDADE & 0.1617 \\
\hline FUZZY SOLOS & 0.0991 \\
\hline FUZZY DISTÂNCIA DE RIOS & 0.2844 \\
\hline FUZZY DISTÂNCIA DE ESTRADAS & 0.1879 \\
\hline
\end{tabular}

QUADRO 5 - PESOS CALCULADOS PARA CADA VARIÁVEL

Razão de Consistência = 0,02 (Portanto aceitável) 
GUIMARÃES, I. M, P.; CANEPARO, S. C. Identificação de áreas adequadas à implantação de infra-estrutura...

A distância de rios aparece como o critério ao qual foi atribuído o maior peso, ou seja assegurar que o limite da área de preservação permanente não seja afetado, por ocasião da implantação da infra-estrutura, por si só determina sua prioridade. A vegetação vem em segundo lugar, ressaltando a importância da conservação deste bioma e justificando a criação do Parque Nacional. Em terceiro lugar a distância de estradas vem balizando, como foi comentado anteriormente, a definição das áreas mais apropriadas para locar a infra-estrutura, visando principalmente a facilidade de acesso sem que haja a necessidade de impactar o meio com a abertura de novas estradas e considerando que ao longo delas o meio natural já deva estar bastante alterado pela ação antrópica. Respectivamente em quarto e quinto lugares aparecem a declividade e o solo, itens que do ponto de vista construtivo não apresentam grandes dificuldades, visto que, atualmente, as técnicas construtivas apresentam inúmeras soluções viáveis para vencer possíveis limitações.
O último passo no processo de agregação dos fatores é a aplicação da regra de decisão, utilizando-se o método de agregação por múltiplos critérios denominado Combinação Linear Ponderada (Weight Linear Combination - WCL), onde cada fator é multiplicado por seu peso e após a soma dos resultados multiplicam-se as restrições Booleanas (neste caso as áreas de preservação permanente, as estradas e o perímetro externo) para eliminar as áreas que não interessam ao objeto deste estudo, este cálculo é feito pixel a pixel, gerando assim um mapa de áreas potenciais, com valores variando de 0 a 255 (EASTMAN, 1998).

O procedimento WCL permite uma compensação completa entre todos os fatores. O grau com que um fator pode compensar o outro é determinado pelo seu peso. Na presente pesquisa um alto peso de aptidão na distância de estradas pode facilmente compensar um baixo peso de aptidão de declividade em um mesmo local. Na imagem resultante este local terá uma aptidão elevada.

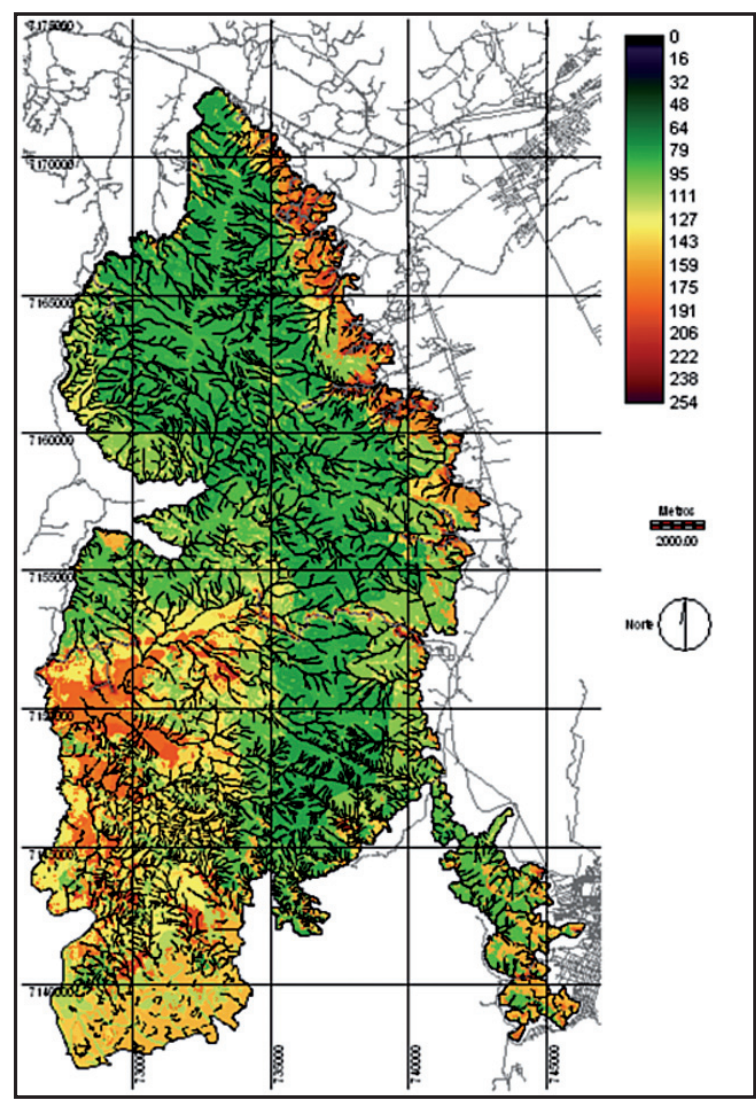

FIGURA 3 - ÁREAS POTENCIAIS PARA A IMPLANTAÇÃO DA INFRA-ESTRUTURA ARQUITETÔNICA NO PARQUE NACIONAL SAINT-HILAIRE/LANGE

FONTE: Serviço Geológico nos Municípios. Convênio IBAMA - MINEROPAR, 2005. 
GUIMARÃES, I. M, P.; CANEPARO, S. C. Identificação de áreas adequadas à implantação de infra-estrutura...

A imagem resultante da Combinação Linear Ponderada pode ser observada a seguir (Figura 3 ) onde é possível observar a variação de níveis de potencialidade, na qual cada pixel representa o valor recebido em toda ação que considerou os critérios escolhidos e os pesos a eles atribuídos, os pixels com maiores valores, ou seja próximos a 255 , representados por cores mais avermelhadas, são considerados em áreas que apresentam maior potencial a implantação da infra-estrutura arquitetônica, e pixels com valores tendendo a 0 , são considerados em locais de baixa potencialidade, devido a fatores limitantes como, por exemplo, alta classe de declive, cobertura vegetal inadequada ao objetivo da análise, grande distância de estradas, etc. Este mapa de áreas potenciais é resultante da integração dos mapas de vegetação, declividade, solos, distância de rios e distância de estradas.

Posteriormente, com o objetivo de especificar ainda mais o objeto da análise, a imagem gerada, foi reclassificada em 5 intervalos de potencialidade, a partir da interpretação visual do histograma resultante da mesma, que é apresentado a seguir na Figura 4.

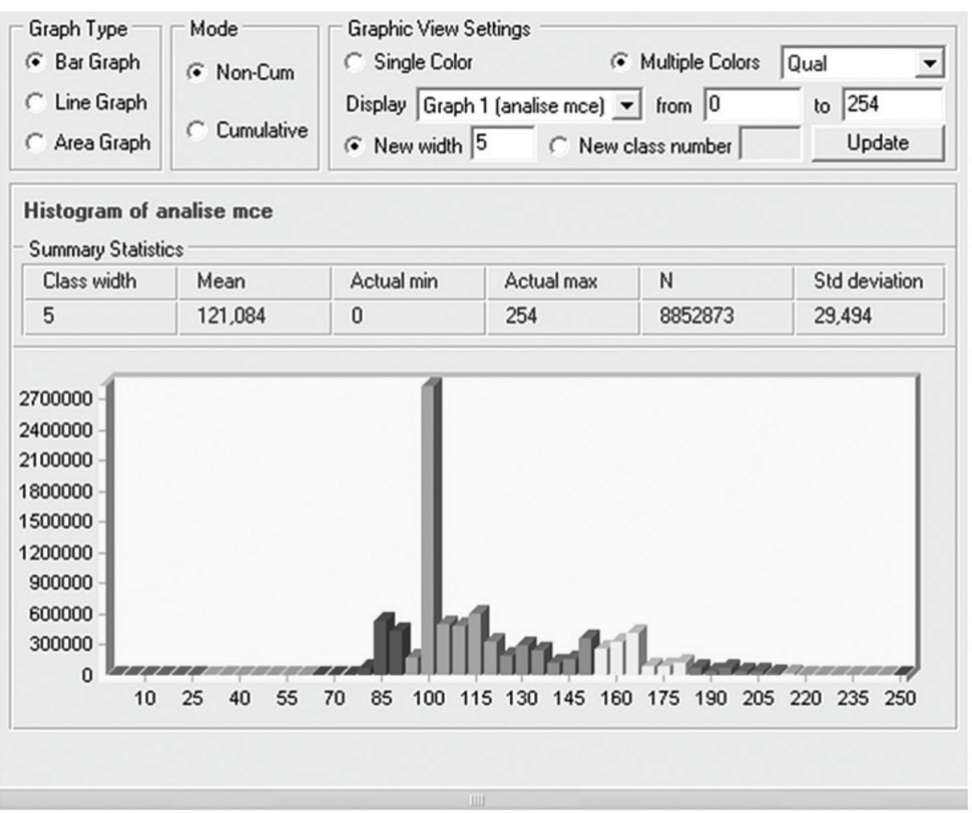

FIGURA 4 - HISTOGRAMA DA IMAGEM GERADA PELA ANÁLISE DE MÚLTIPLOS CRITÉRIOS ATRAVÉS DA COMBINAÇÃO LINEAR PONDERADA

FONTE: Software Idrisi Andes.

O histograma acima apresentado refere-se à freqüência de ocorrência, em número de pixels, das classes potenciais, variando do maior valor potencial encontrado ao menor valor potencial.

As classes potenciais foram reagrupadas de acordo com:

Ótima - sem limitações para a implantação da infra-estrutura. Intervalo variando de 255 a 220.

Boa - com poucas limitações para a implantação da infra-estrutura. Intervalo variando de 220 a 185.

Moderada - com limitações que requerem medidas intensas a implantação da infra-estrutura. Intervalo variando de 185 a 155 .

Ruim - limitações severas e permanentes a implantação da infra-estrutura. Intervalo variando de 155 a 125.

Péssima - inadequadas a implantação da infraestrutura . Intervalo variando de 125 a 0.
Sabe-se no entanto que dentro de cada faixa elencada acima, ou seja, para cada uma das cinco classes potencias, existe uma variação de valores, onde áreas com aptidão similar não possuem necessariamente o mesmo grau de limitação ou potencialidade.

Dentro da classe 1 - Ótima, por exemplo, serão classificadas áreas que apesar de pertencerem à classe de maior potencial, podem conter pequenas restrições em uma ou mais variáveis, que são compensadas por grandes potencialidades encontradas em outras.

Este procedimento de agregação faz parte da técnica da Combinação Linear Ponderada, baseada nas médias a qual coloca análise no meio do caminho, ou seja, nenhum risco extremo e nenhum extremo de aversão ao risco. Ou seja, os fatores compensam-se uns aos outros. 
Cabe aqui ressaltar a importância de uma posterior avaliação de campo, a fim de validar ou não a tomada de decisão, quanto ao objeto da análise desta pesquisa.

A Figura 5 representa a imagem MCE reclassificada.

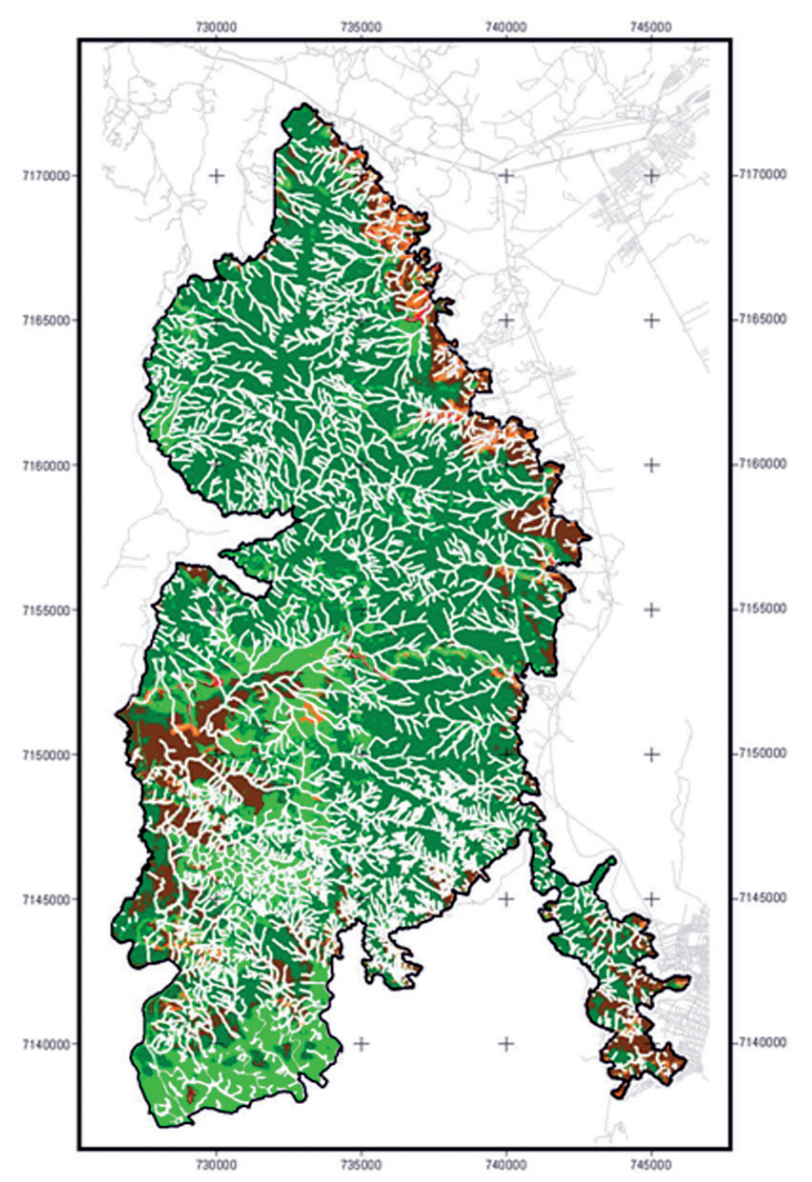

\section{Classes potenciais de infra-estrutura}

\author{
Legenda

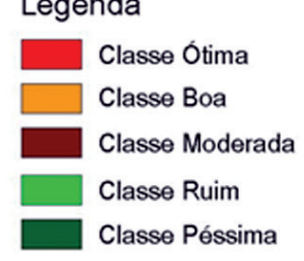

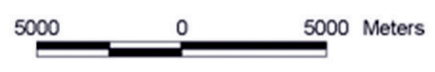

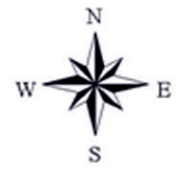

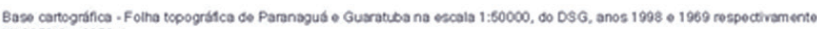
Mi $2858 \cdot 2 \theta 2858 \cdot 4$

Sistema Universal Transwersa do Mercator Dasun Vertcal Imblutu - Sarta Catarna

Serrico Godispico nos Munidiplices COAntrioloma

FIGURA 5 - ÁREAS POTENCIAIS PARA A IMPLANTAÇÃO DA INFRA-ESTRUTURA ARQUITETÔNICA NO PARQUE NACIONAL SAINTHILAIRE/LANGE.

FONTE: Base cartográfica - Folha topográfica de Paranaguá e Guaratuba, escala 1:50.000, do DSG, anos 1998 e 1969 , respectivamente. MI 2858-2 e 2858-4. Serviço Geológico nos Municípios. Convênio IBAMA - MINEROPAR

\section{ANÁLISE E DISCUSSÃO DOS RESULTADOS}

\section{CARACTERIZAÇÃO DAS CLASSES POTENCIAIS}

A expressão territorial reservada para a classe de Potencial 1 - Ótima, apresenta-se muito pequena com apenas 63 ha, cálculo obtido através da análise do histograma gerado da imagem MCE reclassificada, em relação a área total do PARNA com 35888 ha. Com o objetivo de analisar a ocorrência de cada variável tanto na classe de maior potencial como nas demais, serão feitos cruzamentos caso a caso. 
GUIMARÃES, I. M, P.; CANEPARO, S. C. Identificação de áreas adequadas à implantação de infra-estrutura...

\begin{tabular}{|c|c|c|c|c|c|}
\hline \multirow{2}{*}{ VEGETAÇÃO } & \multicolumn{5}{|c|}{ CLASSES DE POTENCIAL PARA IMPLANTAÇÃO DA INFRA-ESTRUTURA (HA) } \\
\hline & 1. ÓTIMA & 2. BOA & 3. MODERADA & 4. RUIM & 5. PÉSSIMA \\
\hline F.O.D Terras Baixas (SH) & 0.0 & 0.0 & 0.0 & 0.8 & 85.2 \\
\hline F.O.D Terras Baixas (SSH, NH) & 0.0 & 0.0 & 0.0 & 6.3 & 565.7 \\
\hline F.O.D Aluvial & 0.0 & 0.0 & 13.2 & 399.1 & 652.5 \\
\hline F.O.D Submontana & 0.0 & 2.5 & 60.7 & 1821.7 & 11220.5 \\
\hline F.O.D Montana & 0.0 & 0.0 & 0.0 & 36.5 & 2122.7 \\
\hline F.O.D Altomontana & 0.0 & 0.0 & 0.0 & 0.0 & 86.8 \\
\hline Campos de Altitude & 0.0 & 0.0 & 0.0 & 0.0 & 7.9 \\
\hline F.P.I m Campos Salinos & 0.0 & 0.0 & 0.2 & 224.6 & 0.8 \\
\hline F.P.I m Manguezais & 0.0 & 0.0 & 4.4 & 862.9 & 1.0 \\
\hline F.P.I.F Várzeas & 0.0 & 3.8 & 368.6 & 20.6 & 0.4 \\
\hline F.P.I.F Caxetais & 0.0 & 26.2 & 615.3 & 10.1 & 0.4 \\
\hline F.P.I.M Restinga (herb. Arb.) & 0.0 & 2.9 & 11.9 & 0.0 & 0.0 \\
\hline F.P.I.M Restinga Arbórea & 0.0 & 0.5 & 19.7 & 0.7 & 0.0 \\
\hline Fase Inicial de Capoeira & 23.9 & 192.2 & 618.9 & 24.2 & 0.0 \\
\hline Fase Intermediária de Capoeirão & 34.2 & 431.8 & 1470.2 & 38.8 & 0.0 \\
\hline Agropecuária e Outros & 5.0 & 16.2 & 18.9 & 0.7 & 0.0 \\
\hline
\end{tabular}

TABELA 1 - CLASSES DE VEGETAÇÃO X CLASSES DE POTENCIAL

FONTE: Cruzamento dos planos gerados no software IDRISI ANDES

Observa-se na Tabela 1, que a classe de potencial 1 - Ótima, em relação a variável vegetação, apresenta apenas áreas com Agropecuária e outros, Fase Intermediária de Capoeirão e Fase Inicial de Capoeira, identificadas pela sua elevada antropização. A medida que as classes de potencial ficam mais restritivas verifica-se o aparecimento de vegetação de grande porte, que requerem maior atenção em termos de preservação.

\begin{tabular}{|c|c|c|c|c|c|}
\hline \multirow{2}{*}{ CLASSES DE DECLIVE } & \multicolumn{5}{|c|}{ CLASSES DE POTENCIAL PARA IMPLANTAÇÃO DA INFRA-ESTRUTURA (HA) } \\
\hline & 1. ÓTIMA & 2. BOA & 3. MODERADA & 4. RUIM & 5. PÉSSIMA \\
\hline $0-5 \%$ & 7.6 & 110.2 & 1030.2 & 1763.4 & 1154.6 \\
\hline $5-12 \%$ & 15.9 & 98.4 & 188.0 & 692.1 & 361.4 \\
\hline $12-30 \%$ & 37.8 & 266.8 & 621.6 & 772.1 & 3554.6 \\
\hline $30-47 \%$ & 1.7 & 132.3 & 808.8 & 137.9 & 5154.9 \\
\hline Maior $47 \%$ & 0.3 & 68.3 & 553.4 & 81.5 & 4518.3 \\
\hline TOTAL (ha) & 63.2 & 676.1 & 3202.1 & 3447.0 & 14743.8 \\
\hline
\end{tabular}

TABELA 2 - CLASSES DE DECLIVE X CLASSES DE POTENCIAL

FONTE: Cruzamento dos planos gerados no software IDRISI ANDES.

Percebe-se na Tabela 2 que a classe de potencial 1 - Ótima, possui apenas 63,2 ha destinados à implantação da infra-estrutura sendo que deste total apenas 2,0 ha encontram -se em declividades superiores a $30 \%$.

Entretanto ocorre um aumento significativo de áreas, a medida que se desloca a avaliação em direção a classe de potencial 5- Péssima. Em uma análise preliminar este fato parece incorreto, já que a classe 5 apresenta 1.154,6 ha entre as declividades de 0 a 5\%, índice considerado ideal ao objetivo desta pesquisa. No entanto deve-se ressaltar que as áreas das classes de menor potencial, apesar de expressivas, certamente apresentam limitações no que se referem as demais variáveis, que serão discutidas a seguir (Ex: áreas de mangue, solos hidromórficos, ocorrem em declividades bem baixas). 
GUIMARÃES, I. M, P.; CANEPARO, S. C. Identificação de áreas adequadas à implantação de infra-estrutura...

\begin{tabular}{|c|c|c|c|c|c|}
\hline \multirow{2}{*}{ CLASSES DE SOLOS } & \multicolumn{5}{|c|}{ CLASSES DE POTENCIAL PARA IMPLANTAÇÃO DA INFRA-ESTRUTURA (HA) } \\
\hline & 1. ÓTIMA & 2. BOA & 3.MODERADA & 4. RUIM & 5. PÉSSIMA \\
\hline PVa1 & 15.6 & 200.8 & 322.9 & 560.8 & 490.0 \\
\hline $\mathrm{Ca} 12+\mathrm{LV} a 3$ & 10.5 & 96.9 & 155.1 & 61.5 & 75.6 \\
\hline Cd11 + PVa3 & 0.0 & 0.4 & 11.5 & 3.9 & 66.8 \\
\hline $\mathrm{Ca} 11+\mathrm{PVa} 3$ & 0.0 & 3.7 & 26.7 & 99.6 & 522.0 \\
\hline $\mathrm{Ca} 12$ + PVa3 & 4.2 & 38.4 & 139.6 & 28.8 & 235.0 \\
\hline $\mathrm{Ca} 26+\mathrm{PVa} 3$ & 0.0 & 0.2 & 0.8 & 14.9 & 122.1 \\
\hline $\mathrm{Ca} 24+\mathrm{PVa} 3$ & 0.8 & 5.4 & 48.1 & 52.7 & 356.5 \\
\hline Ca31 & 0.0 & 0.4 & 3.0 & 34.2 & 359.6 \\
\hline $\mathrm{Ca9}$ & 2.4 & 1.4 & 0.3 & 96.7 & 24.3 \\
\hline Ca11 & 11.7 & 73.5 & 282.2 & 307.8 & 1873.1 \\
\hline Ca12 & 8.4 & 101.7 & 488.8 & 89.1 & 2088.2 \\
\hline $\mathrm{Ca} 12$ + Ca22 & 5.8 & 65.6 & 403.7 & 153.1 & 3817.8 \\
\hline Ca17 & 0.0 & 0.0 & 0.0 & 0.0 & 21.0 \\
\hline $\mathrm{Ca} 21$ & 0.0 & 0.0 & 8.9 & 5.4 & 106.5 \\
\hline $\mathrm{Ca} 14+\mathrm{Ca} 9$ & 3.2 & 59.2 & 53.8 & 713.1 & 82.3 \\
\hline $\mathrm{Ca} 12$ + Ra8 & 0.0 & 0.8 & 16.0 & 9.3 & 522.0 \\
\hline $\mathrm{Ca} 17$ + Ra8 & 0.2 & 2.6 & 4.7 & 6.1 & 150.4 \\
\hline $\mathrm{Ca} 24+\mathrm{Ra} 10$ & 0.0 & 0.1 & 2.7 & 16.2 & 157.7 \\
\hline Сa30 +Re1 & 0.0 & 0.0 & 0.0 & 7.1 & 14.5 \\
\hline $\mathrm{Ca} 12+\mathrm{Ca} 28+\mathrm{Ra} 8$ & 0.0 & 0.0 & 0.6 & 13.0 & 1204.7 \\
\hline $\mathrm{Ca} 12+\mathrm{PVa} 3+\mathrm{AR} 1$ & 0.0 & 2.5 & 14.8 & 22.3 & 21.7 \\
\hline $\mathrm{Ca} 22$ + Ra8 + AR1 & 0.0 & 0.0 & 0.0 & 0.3 & 69.3 \\
\hline $\mathrm{Ca} 8$ + Ra11 + AR1 & 0.0 & 0.7 & 0.1 & 4.2 & 360.1 \\
\hline Ca9 + HGP2 & 0.0 & 0.0 & 20,1 & 40.8 & 128.2 \\
\hline $\mathrm{Ra} 1$ & 0.0 & 0.0 & 0.0 & 8.2 & 108.8 \\
\hline $\mathrm{Ra} 4+\mathrm{AR} 1$ & 0.0 & 0.0 & 0.0 & 0.0 & 255.0 \\
\hline $\mathrm{AR} 1$ + Ra1 & 0.0 & 0.0 & 0.0 & 0.0 & 259.2 \\
\hline HGP2 + Ca14 & 0.0 & 20.7 & 1155.4 & 244.9 & 1232.0 \\
\hline HGP1 + Ad1 & 0.3 & 1.1 & 44.9 & 873.8 & 61.3 \\
\hline $\mathrm{P}+\mathrm{PH} 1$ & 0.0 & 0.0 & 17.5 & 20.0 & 86.4 \\
\hline TOTAL & 63.2 & 676.1 & 3202.1 & 3447.0 & 14743.8 \\
\hline
\end{tabular}

TABELA 3 - CLASSES DE SOLOS X CLASSES DE POTENCIAL

FONTE: Cruzamento dos planos gerados no software IDRISI ANDES.

Na Tabela 3, apresentada anteriormente, percebe-se que a classe de potencial 1 - Ótima, possui uma maior concentração de áreas entre as primeiras unidades de mapeamento, sendo que para as demais unidades, as áreas são inexpressivas ou inexistentes. Demonstrando claramente que a metodologia aplicada foi eficiente no que se refere aos critérios adotados, nos quais os solos Hidromórficos, Aluviais, Litólicos e Afloramento de Rochas apresentam os menores potenciais na classificação devido as suas restrições quanto à implantação da infra-estrutura. 
GUIMARÃES, I. M, P.; CANEPARO, S. C. Identificação de áreas adequadas à implantação de infra-estrutura...

\begin{tabular}{cccc}
\hline CLASSES DE POTENCIAL PARA A IMPLANTAÇÃO & \multicolumn{3}{c}{ DISTÂNCIA DE RIOS (M) } \\
\cline { 2 - 4 } DA INFRA-ESTRUTURA & MÍNIMO & MÁXIMO & 420.1 \\
\hline 1. Ótima & 51.5 & 459.2 & 107.8 \\
2. Boa & 51.5 & 805.0 & 118.9 \\
3. Moderada & 51.5 & 780.3 & 149.8 \\
4. Ruim & 51.5 & 780.1 & 129.6 \\
5. Péssima & 51.5 & & \\
\hline
\end{tabular}

TABELA 4 - DISTÂNCIA DE RIOS X CLASSES DE POTENCIAL

FONTE: Cruzamento dos planos gerados no software IDRISI ANDES.

Na Tabela 4, percebe-se que a distância mínima das áreas potenciais, em relação aos rios, é igual para todas as classes, ou seja, 51,5 metros. Devendo-se ao fato da inclusão de uma área de restrição de 50,0 metros, dita Área de Preservação Permanente, ao longo de todos os cursos d'água e nascentes. Já a distância máxima que uma área potencial possa se encontrar em relação aos rios, apresenta um valor dentro de um limite perfeitamente aceitável no que se refere aos impactos que a infra-estrutura possa causar ao meio local.

\begin{tabular}{cccc}
\hline CLASSES DE POTENCIAL PARA A IMPLANTAÇÃO & \multicolumn{3}{c}{ DISTÂNCIA DE ESTRADAS (M) } \\
\cline { 2 - 4 } DA INFRA-ESTRUTURA & MÍNIMO & MÁXIMO & MÉDIA \\
\hline 1. Ótima & 7.1 & 126.6 & 12791.9 \\
2. Boa & 7.1 & 12851.4 & 2266.3 \\
3. Moderada & 7.1 & 13652.0 & 5350.4 \\
4. Ruim & 7.1 & 13106.4 & 2613.6 \\
5. Péssima & 49.5 & & \\
\hline
\end{tabular}

TABELA 5 - DISTÂNCIA DE ESTRADAS X CLASSES DE POTENCIAL

FONTE: Cruzamento dos planos gerados no software IDRISI ANDES.

Na Tabela 5, apresentada acima, pode-se perceber que a classe 1 - Ótima, com uma distância máxima de 126,6 metros, representa claramente a eficiência dos critérios adotados. Ao considerar que as áreas adequadas, deveriam estar próximas às estradas ou caminhos já existentes, limitadas a uma distância máxima de 200 metros, a fim de evitar um impacto ambiental mais acentuado sobre o meio.

Na análise da distância mínima, a classe 1 Ótima, com 7,1 metros, representa novamente a eficiência dos critérios adotados, partindo do princípio que, a localização da infra-estrutura, necessária ao apoio de visitantes e pessoal administrativo, deve estar próxima às estradas, com o objetivo de facilitar o acesso e reduzir o impacto ambiental.

\section{CARACTERIZAÇÃO SOMENTE DAS ÁREAS COM CLASSE DE POTENCIAL 1 - ÓTIMA}

Com o objetivo de caracterizar somente as áreas com classe de Potencial 1- Ótima, foi estipulada uma metragem baseada em um levantamento hipotético, da dimensão mínima da área, necessária à implantação das obras de apoio à visitação como: centro de visitantes, lanchonete, estacionamento, camping, sanitários; e de apoio administrativo, como: sede da administração, casa do chefe da unidade, alojamento de funcionários e pesquisadores, oficinas, estacionamento, estimada em 1.500,0 m2.

Para que fosse possível a identificação de cada uma das áreas iguais ou superiores a $1.500,0 \mathrm{~m}^{2}$, os polígonos do plano de informação contendo somente as áreas da classe de Potencial 1 - Ótima foram desagregados e cada área recebeu um identificador. Posteriormente estas áreas foram calculadas, das quais, 100 apresentaram dimensão igual ou superior a $1.500,0 \mathrm{~m}^{2}$.

Com o objetivo de realizar uma caracterização mais detalhada, destas áreas potenciais foram selecionadas 20 do total, por apresentarem as maiores expressões territoriais, ou seja maiores que $7.000,0 \mathrm{~m}^{2}$. A seguir com o objetivo de analisar a ocorrência de cada variável (vegetação, declividade, solos, distância de rios e estradas) foram realizados cruzamentos caso a caso para todas as 20 áreas da amostragem. 
GUIMARÃES, I. M, P.; CANEPARO, S. C. Identificação de áreas adequadas à implantação de infra-estrutura...

Dos resultados deste procedimento foi possível observar a identificação de apenas as coberturas vegetais de Fase inicial de Capoeira, Fase intermediária de Capoeirão e Agropecuária e outros. Estas classes de vegetação, identificadas nas proximidades das estradas e limites do PARNA, representam as menores limitações quanto à implantação da infra-estrutura, por se encontrarem já bastante antropizadas, validando a metodologia empregada, a qual encerra em seus objetivos, também assegurar a preservação das demais classes de vegetação.

Constatou-se também que para a maioria das áreas selecionadas a ocorrência em declives superiores a $30 \%$ é bem reduzida. Para a classe de declive que varia de $0 \%$ a $5 \%$ verifica-se sua ocorrência em todas as unidades selecionadas da amostra. Percebe-se no entanto as maiores dimensões territoriais inseridas na classe que varia de $5 \%$ a $12 \%$ de declividade.

Quanto ao Solo a unidade de mapeamento PVa1 é considerada, nesta análise, como sendo o melhor solo para a implantação da infra-estrutura, e na amostragem de 20 áreas, esta unidade ocorre apenas 05. Embora pareça sua ocorrência pouco expressiva, apresenta um total de $73.225,0 \mathrm{~m}^{2}$, área muito maior do que a mínima necessária estipulada hipoteticamente de $1.500,0 \mathrm{~m}^{2}$. As demais áreas da amostra apresentam a ocorrência das seguintes unidades de mapeamento do solo: Ca12+LVa3, Ca11+PVa3, Ca12+PVa3, Ca24+PVa3, Ca9, Ca11, Ca12 e Ca14+Ca9.

Quanto a variável distância de rios observa-se que as áreas analisadas encontram-se a uma distância mínima, variando em um intervalo de 51,5 metros a 152,3 metros, atendendo satisfatoriamente os requisitos utilizados na análise de suporte à decisão, que consideravam como áreas potenciais à implantação da infra-estrutura arquitetônica, somente aquelas que se encontram acima do limite de Preservação Permanente das Matas Ciliares.

E finalmente em relação a variável distância de estradas considerando a amostragem das 20 áreas de potencial 1-Ótima, observa-se que, estas áreas encontram-se distantes o suficiente para atender os requisitos utilizados na análise de suporte à decisão, tanto para os valores mínimos, variando de 7,1 metros a 35,4 metros, quanto para os valores máximos que variam de 58,3 metros a 107,4 metros.

A caracterização mais detalhada das áreas de Potencial 1, consideradas como as mais adequadas à implantação da infra-estrutura, em relação as variáveis analisadas, teve como objetivo a sondagem dos resultados obtidos. No entanto, faz-se necessária uma avaliação em campo das áreas selecionadas, a fim de identificar e discutir os elementos que determinaram os resultados levando em consideração as características físicas da paisagem e a legislação ambiental.

\section{AVALIAÇÃO DE CAMPO}

Das 20 áreas avaliadas anteriormente 02 foram selecionadas por apresentarem as maiores expressões territoriais, com $30.650,0 \mathrm{~m} 2$ e $40.375,0 \mathrm{~m} 2$ respectivamente, além da proximidade entre elas. Com o intuito de facilitar a localização das mesmas, estas foram identificadas com coordenadas UTM e transferidas para um GPS de navegação.

Estas áreas têm significativa importância, pois se encontram muito próximas da estrada, condição considerada essencial, pois além do fácil acesso, contam a existência de rede elétrica e de abastecimento de água, reduzindo os custos operacionais para viabilizar um canteiro de obra.

$\mathrm{Na}$ avaliação de campo foi possível observar um relevo pouco acidentado, próximo à estrada, e em alguns pontos pode-se considerar uma declividade variando de $0 \%$ a $5 \%$. Estas áreas contam com uma característica praticamente linear, ou seja, cujas extensões correm praticamente paralelas à estrada, porém o relevo torna-se mais acentuado a medida que o observador adentra a mesma.

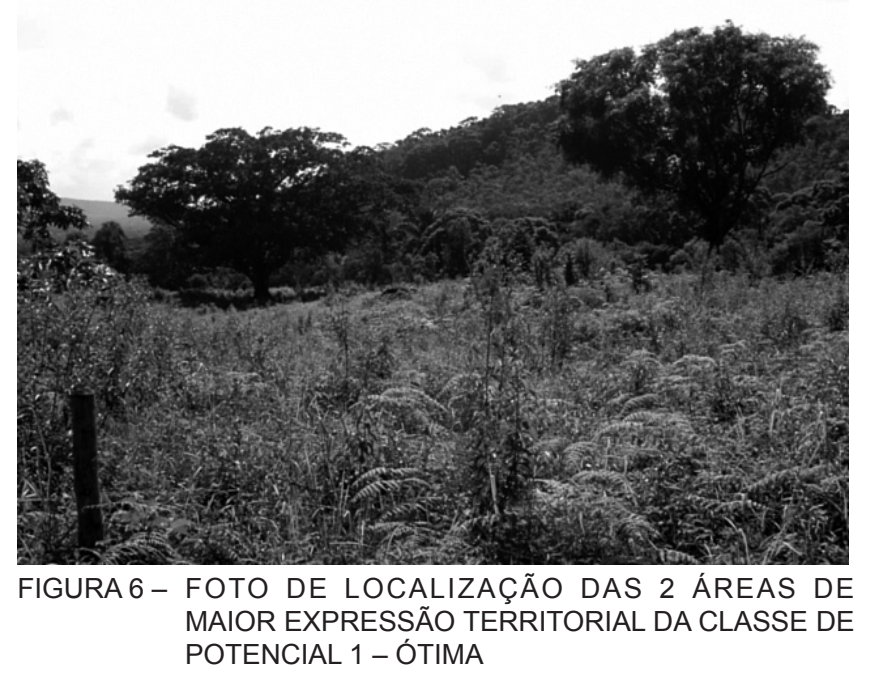

FONTE: A autora

Pela avaliação de campo, apoiada sobre as técnicas empregadas em laboratório para a definição de áreas potenciais, estas atendem perfeitamente ao objetivo proposto para a implantação da infra-estrutura arquitetônica. 
GUIMARÃES, I. M, P.; CANEPARO, S. C. Identificação de áreas adequadas à implantação de infra-estrutura...

\section{CONSIDERAÇÕES FINAIS}

Com o intuito de contribuir com o planejamento e futura implantação do Plano de Manejo para a área do Parque Nacional Saint-Hilaire/Lange, no que diz respeito à identificação de áreas adequadas (zoneamento) para a implantação da infra-estrutura arquitetônica, o presente estudo buscou primeiramente o reconhecimento e o entendimento do meio físico. Uma vez que os impactos inerentes da ação antrópica (obras de infra-estrutura) sobre o meio ambiente, estão intimamente ligados à dinâmica natural, associados à localização e intensidade de uso das instalações.

Portanto, para a prevenção ou minimização destes impactos, a metodologia proposta, que emprega o uso de Sistemas de Informação Geográfica e trata com facilidade o manuseio de um grande conjunto de dados do meio físico, dando suporte a tomada de decisão, mostrou-se eficaz. E além da identificação das áreas potenciais, o conjunto de mapas temáticos gerados, e o banco de dados georreferenciados das informações obtidas, fornece o embasamento para a realização de novos cruzamentos, gerando novas informações. Assim o geoprocessamento pode passar a integrar praticamente todas as etapas, no que diz respeito ao zoneamento da área em questão

Diante da análise e das discussões dos resultados, pode-se afirmar que na caracterização das classes potenciais, a ocorrência de cada variável (vegetação, declividade, solo, distância de rios e distância de estradas) mostrou distribuição coerente entre os diferentes graus de limitações de cada classe, validando os critérios utilizados na classificação de cada uma (melhores classes de cobertura vegetal, limite de declividade, solos com menor tendência a processos erosivos, distância de rios e proximidade de estradas).

$\mathrm{Na}$ caracterização específica da classe de Potencial 1 - Ótima, analisando áreas maiores ou iguais a $1.500,0 \mathrm{~m}^{2}$. Foi possível constatar a mesma eficiência, descrita acima, da metodologia empregada observada nas vinte áreas da amostragem, onde não ocorreram discrepâncias significativas na análise das mesmas.

$\mathrm{Na}$ avaliação de campo das 02 áreas selecionadas foi possível validar a metodologia empregada na análise.

Portanto, considerando a importância que os Parques Nacionais representam na preservação do meio ambiente, é cada vez mais necessário que as ações antrópicas sejam absolutamente compatíveis com as potencialidades e restrições dos aspectos naturais, daí a necessidade da elaboração de projetos que considerem além das condições atuais do meio físico as prováveis implicações após sua implantação, e que permitam calibrações, ou seja, ajustes futuros dentro de um planejamento contínuo, participativo e flexível.

\section{REFERÊNCIAS}

BIGARELLA, J. J. et al. A Serra do Mar e a Porção Oriental do Estado do Paraná. Curitiba: SEPL, 1978.

BORNSCHEIN, M. R.; REINERT, B. L.; OLMOS, F. Alterações nos limites do Parque Nacional Saint-Hilaire/Lange (Paraná). Parecer Técnico da BirdLife International, Brasil Programme. Curitiba, 2003.

DE BIASI, M. A. Carta clinográfica: os métodos de representação e sua confecção. Revista do Departamento de Geografia, São Paulo, n. 6, 1992.

EASTMAN, J. R. Idrisi for Windows: Intodução e Exercícios Tutoriais - Versão 2. Tradução: Heinrich Hasenack e Eliseu Weber. Porto Alegre: UFRGS - Centro de Recursos Idrisi, 1998.

EMBRAPA. Levantamento de reconhecimento dos solos do estado do Paraná. Curitiba, 1984.

FRANCO, M. A. R. Planejamento ambiental para a cidade sustentável. São Paulo: Annablume/FAPESP, 2001.

IBAMA. Informações sobre o Parque Nacional Saint-Hilaire/ Lange. Disponível em: <http://www.ibama.org.com>. Acesso em: 18/4/2006.
LOPES, O.; LIMA, R. E. Nota preliminar sobre a geologia da Serra da Prata - PR. Boletim Paranaense de Geociências, Curitiba, n. 36. 1985.

MANTOVANI, L. E.; FRITZONS, E. Ambiente Climático da Floresta Ombrófila Mista. In: INTERNACIONAL SYMPOSIUM ON FOREST ECOSSYSTEMS - FOREST 96, 4., Belo Horizonte. Anais... Belo Horizonte, 1996.

ROSS, J. L. S. Geomorfologia, ambiente e planejamento. São Paulo: Contexto, 1990.

ROSS, J. L. S. Geomorfologia aplicada aos EIAs - RIMAs. In: GUERRA, A. J. T.; CUNHA, S. B. da. Geomorfologia e meio ambiente. 3. ed. Rio de Janeiro: Bertrand Brasil, 2000. $372 \mathrm{p}$.

SCHMIDLIN, D. Utilização de técnicas de sensoriamento remoto e sistemas de informações geográficas para atualização e geração do mapa compilado de solos da área de proteção ambiental - APA de Guaratuba (PR). Dissertação (Mestrado) - Departamento de Solos, Universidade Federal do Paraná, Curitiba, 1998. 
SIEDLECK, K. N.; PORTES, M. C. de O.; CIELO FILHO, R. Proposta de adequação dos limites do Parque Nacional Saint-Hilaire/Lange (Serra da Prata) - Estado do Paraná. In: SIMPÓSIO DE ÁREAS PROTEGIDAS - CONSERVAÇÃO NO ÂMBITO DO CONE SUL, 2., Curitiba. Anais... Curitiba, $2003 a$.

. Subsídios técnicos para fixação dos limites definitivos do Parque Nacional Saint Hilaire/Lange. Curitiba: IBAMA, 2003b.
WEBER, E. J.; HASENACK, H. O uso do SIG no ensino de Ciências Ambientais. In: CONGRESSO E FEIRA PARA USUÁRIOS DE GEOPROCESSAMENTO DA AMÉRICA LATINA, 5., 1999, Salvador. Anais... Salvador, 1999.

ZAMBON, K. L. et al. Análise de decisão multicritério na localização de usinas termoelétricas utilizando SIG. Pesquisa Operacional, Rio de Janeiro, v. 25, n. 2, p. 183-199, 2005. 
